\title{
Topical rapamycin for angiofibromas in patients with tuberous sclerosis: how does it work in clinical practice?
}

\author{
Maria Palmetun Ekbäck ${ }^{1,2}$, Desiree Wiegleb Edström ${ }^{3}$ \\ ${ }^{1}$ Department of Dermatology, Örebro University Hospital, 70185 Örebro, Sweden. \\ ${ }^{2}$ Department of Pharmacology and Therapeutic, Region Örebro County Council, 70185 Örebro, Sweden. \\ ${ }^{3}$ Department of Medicin Solna, Karolinska Institute and Department of Dermatology, Karolinska University Hospital, 17176 Stockholm, Sweden.
}

Correspondence to: Dr. Maria Palmetun Ekbäck, Department of Dermatology, Örebro University Hospital, 70285 Örebro, Sweden.

E-mail: maria.palmetun-ekback@regionorebrolan.se

How to cite this article: Palmetun Ekbäck M, Wiegleb Edström D. Topical rapamycin for angiofibromas in patients with tuberous sclerosis: how does it work in clinical practice? Plast Aesthet Res 2016;3:328-34.

Article history:

Received: 31-07-2016

Accepted: $13-10-2016$

Published: 25-10-2016

\section{Key words:}

Tuberous sclerosis,

topical rapamycin,

angiofibroma,

clinical practice

\begin{abstract}
Aim: Topical rapamycin for angiofibromas has been reported to be a new promising treatment. This study aims to report the outcome in clinical practice. Methods: A retrospective clinical follow-up on twenty-three patients who had been prescribed an oral solution of $0.1 \%$ rapamycin, to be applied on facial lesions once a day. Results: Seventeen of 23 patients continued the treatment. Papules and nodules were improved in 8 patients (47\%) and erythema in $12(70 \%)$. Side effects, such as stinging and redness were reported in $35 \%$ of patients. Blood samples were taken from 5 patients and no rapamycin could be detected. All patients who paused the treatment relapsed. Conclusion: Topical rapamycin has a positive effect on angiofibromas with improvement in both erythema and papules even if only applied every second to third day, but continuous treatment is needed.
\end{abstract}

\section{INTRODUCTION}

Tuberous sclerosis complex (TSC) is a dominant autosomal disorder that affects multiple organ systems. The prevalence of the disease is estimated to 1 in 6,000 live births. ${ }^{[1]}$ Spontaneous or inherited mutations in the tumor-suppressor genes TSC1 (9q34) or TSC2 (16p13) are found in $85 \%$ result in activation of the mammalian target of rapamycin complex 1 (mTORC1) leading to uncontrolled formation of hamartomas in the brain, retina, skin, heart, kidneys, and lungs.

These patients should be evaluated by a dermatologist for facial angiofibromas, fibrous cephalic plaques, hypomelanotic macules, ungual fibromas and shagreen patches. ${ }^{[2]}$

Facial angiofibroma is found in $80-90 \%$ of cases and consist of vascular and fibrotic tissue, leading

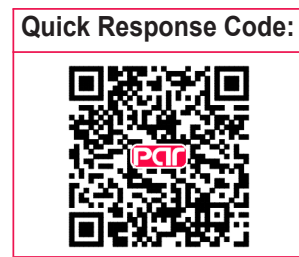


to reddish or skin-coloured papules in the centrofacial area. ${ }^{[3]}$ Patients with these lesions may suffer negative emotional impact and stigmatization. In addition, the angiofibromas can easily bleed after minor trauma. In 2008, Hofbauer et al. ${ }^{[4]}$ treated a patient with oral rapamycin, an mTOR inhibitor, to suppress graft rejection in one patient with tuberous sclerosis who had received a kidney transplant because of renal angiomyolipomas. They could report a marked improvement of facial angiofibromas. ${ }^{[4]}$ In 2010 , Haemel et al. ${ }^{[5]}$ succeeded in preparing a topical ointment which had effect on facial angiofibromas. In 2011, Mutizwa et al. ${ }^{[6]}$ reported that an oral solution with rapamycin could be used on the skin with good result. Since then, there are several case reports ${ }^{[7-10]}$ and studies ${ }^{[11-14]}$ reporting improvement after topical rapamycin applied once or twice daily. ${ }^{[15-18]}$

The aim of this retrospective observational study was to describe the outcome in clinical practice treating angiofibromas in TSC with topical rapamycin.

\section{METHODS}

\section{Patients and methods}

All patients, who had been treated with topical rapamycin between January 2012 through December 2014 at the Dermatology Departments Karolinska University Hospital Stockholm and Örebro University Hospital, were followed up in this retrospective observational evaluation. There were in total 23 patients. Fifteen of the 23 patients had previously been treated with $\mathrm{CO}_{2}$ laser. Sixteen of 23 patients had tuberous-sclerosis-associated neuropsychiatric disorders (TAND) and 18 had severe epilepsy. All 23 patients had been prescribed an oral solution of $0.1 \%$ rapamycin, but told to apply it on all facial lesions once a day. In case of skin irritation the patients had been instructed to refrain from treatment for a couple of days and use a weak topical glucocorticoid cream, and then resume the rapamycin treatment when the skin irritation had subsided. In the beginning of the treatment we instructed the patients/parents to discontinue during the summer, because of uncertainty regarding interaction with sunlight. The summer pause was from mid-June to mid-August 2012. The patients were initially instructed to give blood samples for measurement of serum rapamycin after four weeks of treatment. Treatment photos were taken. Follow-up was done through visits in person or through e-mailed photos, as some patients lived far from the clinics. All evaluations were done by the authors. The authors looked at several photos prior to the evaluation in order to reach consensus about the grading, as there was no standardized grading system at the time for the evaluation. Erythema was graded as no erythema, slight, medium, or severe erythema. Angiofibromas were described as papules $(<5 \mathrm{~mm}$ ) or nodules ( $\geq 5 \mathrm{~mm}$ ). Both effects on papules, nodules and erythema and side effects were evaluated. The results were compared with the pre-treatment photos and graded on the scale: no improvement, improvement or excellent.

\section{Ethical considerations}

This retrospective study is a clinical follow-up of the patients treated with topical rapamycin according to clinical praxis. In Sweden, a formal approval from an Ethics Committee is not needed for a clinical follow-up. This was also discussed with our Ethical Committee. All patients and/or parents got orally and written information about the treatment and potentially side effects and gave their informed consent.

\section{RESULTS}

\section{Clinical results}

Twenty-three patients (10 males) were included in the retrospective observational evalutaion. The mean age was 19 years (range 2-52 years) [Table 1]. The duration of treatment was from 3 weeks to 33 months. Six patients discontinued the treatment. Of these, 2 were lost to follow-up; 2 were put on oral everolimus treatment because of internal hamartomas; and 2 discontinued the treatment after 3 weeks because of intractable side effects, such as skin pain, severe dryness, itching, burning sensations, erythema and swelling [Table 1].

Seventeen patients continued the treatment [Figure 1].

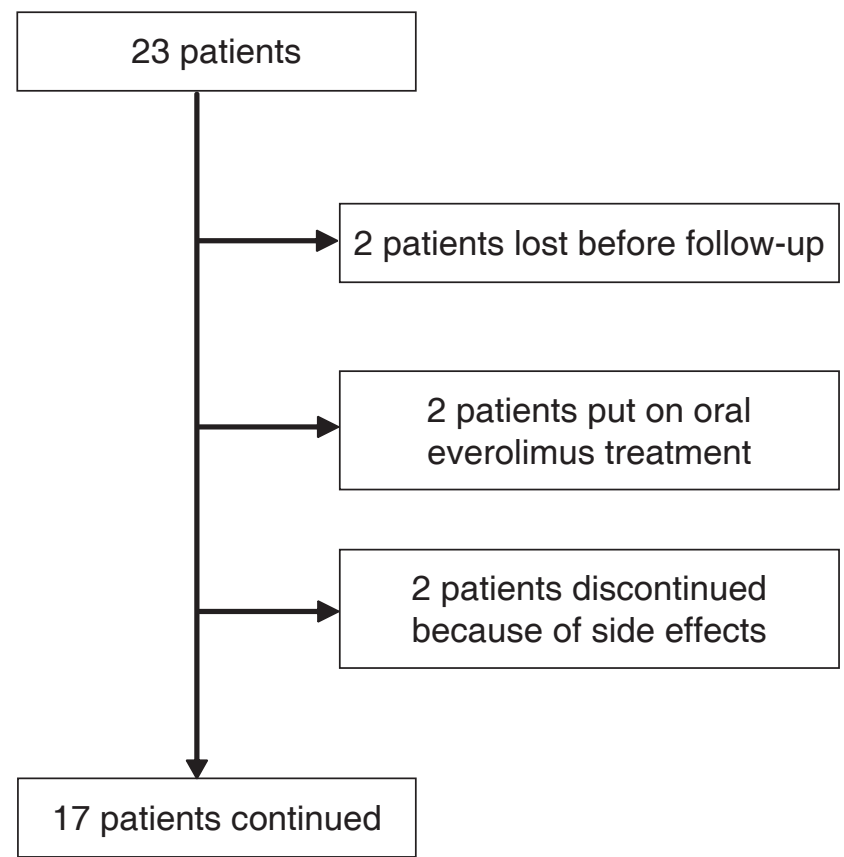

Figure 1: Flow diagram of patient population 
Table 1: Patients and results

\begin{tabular}{|c|c|c|c|c|c|c|c|c|c|c|}
\hline No. & Gender & $\begin{array}{l}\text { Age, } \\
\text { year }\end{array}$ & $\begin{array}{c}\text { Skin lesions } \\
\text { (pre) }\end{array}$ & $\begin{array}{l}\text { Erythema } \\
\text { (pre) }\end{array}$ & $\begin{array}{l}\mathrm{CO}_{2} \\
\text { laser } \\
\text { (pre) }\end{array}$ & $\begin{array}{c}\text { Duration of } \\
\text { treatment }\end{array}$ & $\begin{array}{l}\text { Skin } \\
\text { lesions post } \\
\text { treatment }\end{array}$ & $\begin{array}{c}\text { Erythema } \\
\text { post } \\
\text { treatment }\end{array}$ & $\begin{array}{l}\text { Side } \\
\text { effects }\end{array}$ & $\begin{array}{l}\text { Sirolimus } \\
\text { conc }\end{array}$ \\
\hline 1 & $M$ & 15 & $\begin{array}{l}\text { Papules and } \\
\text { nodules }\end{array}$ & Medium & No & 6 months & Not improved & Not improved & None & Not done \\
\hline 2 & $\mathrm{~F}$ & 4 & Papules & Medium & Yes & 14 months & Improved & Excellent & None & Not done \\
\hline 3 & M & 10 & Papules & Slight & No & $6+3$ months ${ }^{*}$ & Improved & Improved & Dryness & Not detected \\
\hline 4 & $\mathrm{~F}$ & 2 & Papules & Medium & No & 7 months & Excellent & Excellent & None & Not done \\
\hline 5 & $\mathrm{~F}$ & 13 & $\begin{array}{l}\text { Papules and } \\
\text { nodules }\end{array}$ & Medium & Yes & 10 months & Not improved & Improved & Dryness & Not detected \\
\hline 6 & $M$ & 12 & $\begin{array}{l}\text { Papules and } \\
\text { nodules }\end{array}$ & Medium & No & $8+12$ months $^{*}$ & Not improved & Improved & Dryness & Not detected \\
\hline 7 & $M$ & 30 & Papules & Slight & Yes & $1.5+1$ month $^{*}$ & Not improved & $\begin{array}{c}\text { Not } \\
\text { improved }\end{array}$ & Dryness & Not done \\
\hline 8 & $\mathrm{~F}$ & 43 & Papules & Medium & Yes & $9+16$ months $^{*}$ & Excellent & Excellent & None & Not detected \\
\hline 9 & $\mathrm{~F}$ & 9 & Papules & Medium & No & Drop out & - & - & - & Not done \\
\hline 10 & $M$ & 2 & $\begin{array}{c}\text { Fibrous cephalic } \\
\text { Plaque }\end{array}$ & Medium & No & $9+4$ months $^{*}$ & Not improved & $\begin{array}{c}\text { Not } \\
\text { improved }\end{array}$ & None & Not detected \\
\hline 11 & M & 7 & Papules & Medium & No & Drop-out & - & - & - & Not done \\
\hline 12 & M & 19 & Papules & Medium & Yes & $19+7$ months $^{*}$ & Improved & Improved & None & Not done \\
\hline 13 & $\mathrm{~F}$ & 19 & Papules & Medium & Yes & $11+7$ months $^{*}$ & Improved & Improved & None & Not done \\
\hline 14 & $M$ & 18 & Papules & Medium & Yes & $5+14$ months $^{*}$ & Improved & Improved & None & Not done \\
\hline 15 & $M$ & 21 & Papules & Medium & Yes & 3 months & Not improved & $\begin{array}{c}\text { Not } \\
\text { improved }\end{array}$ & None & Not done \\
\hline 16 & $\mathrm{~F}$ & 26 & Papules & Medium & No & 33 months & Improved & Improved & None & Not done \\
\hline 17 & $\mathrm{~F}$ & 29 & Papules & Slight & Yes & 5 months & $\dagger$ & $\dagger$ & $\dagger$ & Not applicable \\
\hline 18 & $\mathrm{~F}$ & 33 & Papules & Medium & Yes & 3 months & $\dagger$ & $\dagger$ & $\dagger$ & Not applicable \\
\hline 19 & $\mathrm{~F}$ & 52 & Papules & Slight & Yes & 3 weeks & Discontinued & & $\begin{array}{l}\text { Dryness, } \\
\text { itching and } \\
\text { swollen }\end{array}$ & Not done \\
\hline 20 & $\mathrm{~F}$ & 9 & Papules & Medium & Yes & $6+5$ months $*$ & Improved & Improved & Itching & Not done \\
\hline 21 & $\mathrm{~F}$ & 10 & Papules & Medium & Yes & $5+6$ & Not improved & Improved & Stinging & Not done \\
\hline 22 & $\mathrm{~F}$ & 16 & Papules & Medium & Yes & 3 weeks & Discontinued & & $\begin{array}{l}\text { Pain, ery- } \\
\text { thema }\end{array}$ & Not done \\
\hline 23 & M & 32 & Papules & Severe & Yes & 1.5 months & Not improved & Excellent & None & Not done \\
\hline
\end{tabular}

*Paused the treatment during summer months; †Received oral rapamycin for internal hamartomas

All patients except three were evaluated during visits where the skin status was compared with the pretreatment photos. Three patients lived far away and were evaluated through photos sent by e-mail. Five patients had blood samples taken for rapamycin measurement but none had detectable rapamycin levels.

Papules were improved in 9 patients (53\%), of whom 2 had results classed as excellent [Figures 2 and 3]. The median treatment time for the patients who responded (improved or excellent results) was 16 months (733 months). The patients who did not respond (not improved results) had a median treatment time of 10 months (1.5-13 months). The 3 patients with both papules and nodules did not improve. The patient with a fibrous cephalic plaque did not respond to treatment. The median age of the patients whose skin lesions were improved was 13 years (2-43 years). The median age of the patients whose skin lesions were not improved was 14 years (2-32 years).
The erythema was improved in 12 of 17 patients $(70 \%)$ [Figure 4$]$, of whom 4 had excellent results [Table 1]. The median age of the patients whose erythema responded (improved and excellent) was 12.5 years (2-43 years) and median treatment time was 12.5 months (1.5-33 months). The median age for the patients whose erythema did not respond was 18 years (2-30 years) and median treatment time was 4.5 months (2.5-13 months). During the summer pause, lesions and erythema recurred.

Initially, rapamycin was prescribed on a daily basis. Six of 17 patients $(35 \%)$ had mild side effects, such as dryness, itching and stinging, but could continue the treatment when using the solution every second to third day. In practice, the treatment was performed every second to third day. The reasons for this were both side effects and compliance problems. Eleven of these 17 patients had $\mathrm{CO}_{2}$ laser treatment 3-5 months [Figures 3, 5, 6 and 7] before rapamycin treatment. 

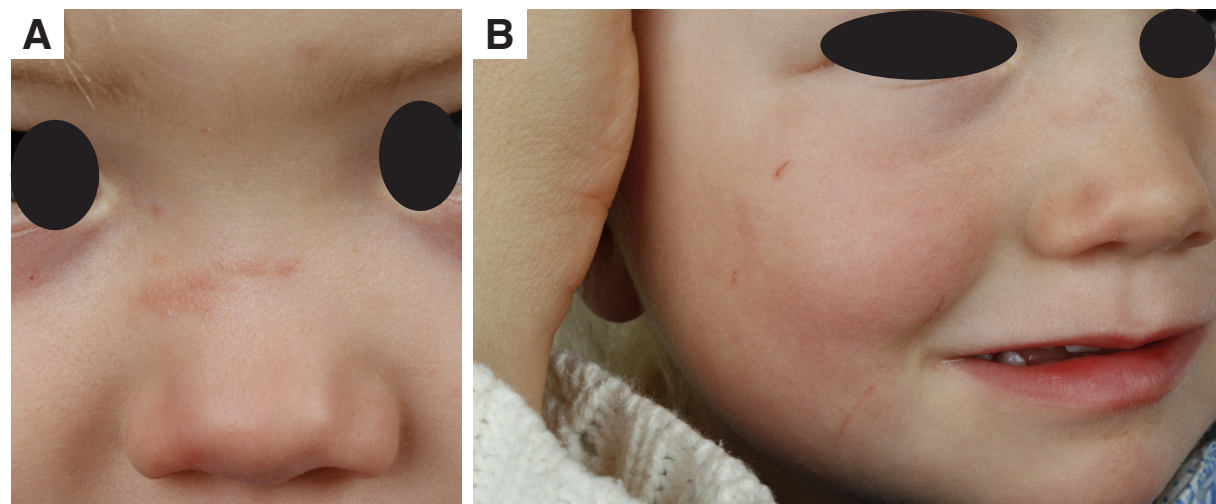

Figure 2: Patient 4. (A) before treatment; (B) after 7 months
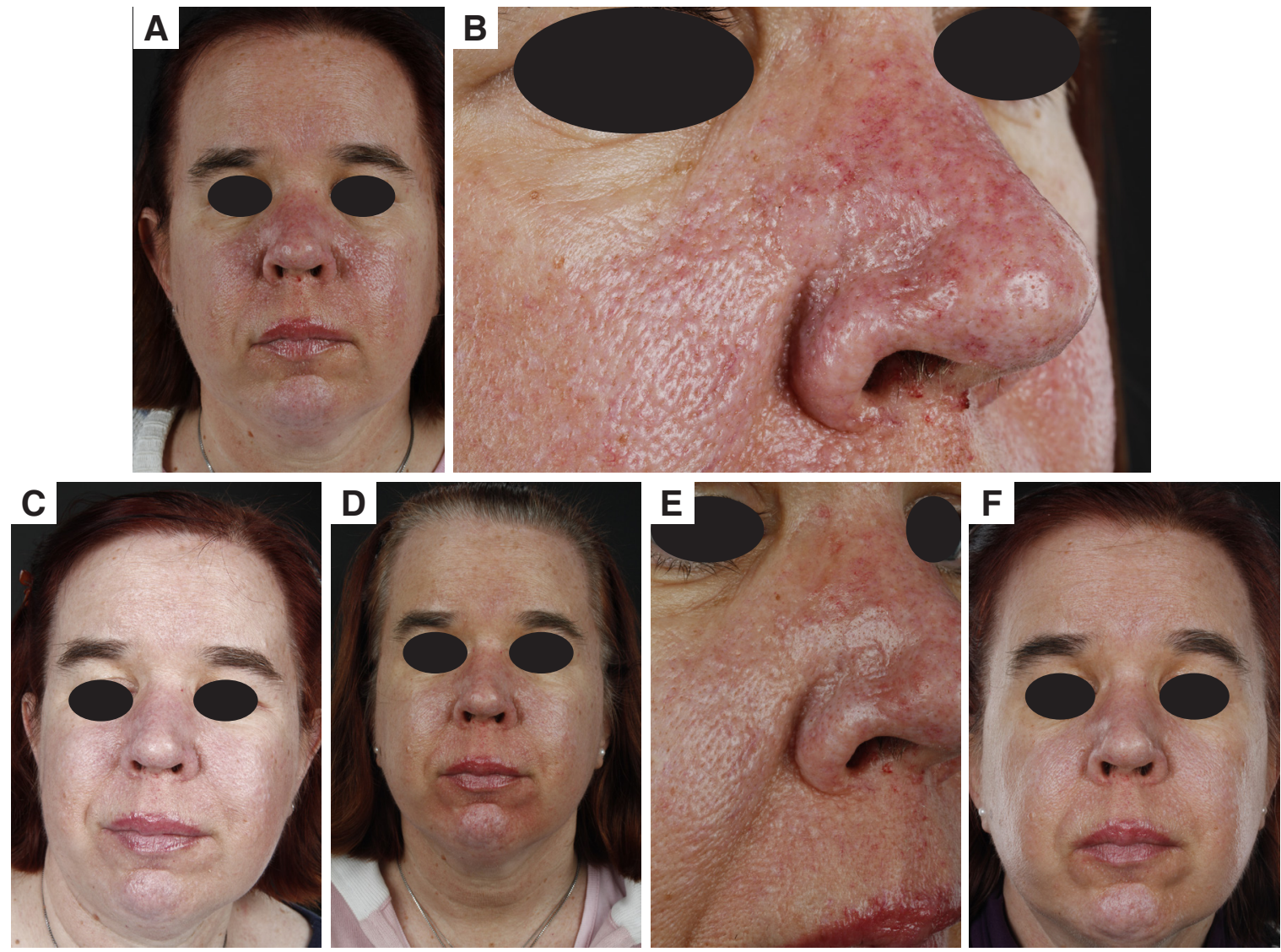

Figure 3: Patient 8. (A) 3 months after $\mathrm{CO}_{2}$ laser and before rapamycin; (B) 3 months after $\mathrm{CO}_{2}$ laser and before rapamycin close-up; (C) after 6 weeks on rapamycin; (D) after 9 months with topical rapamycin; (E) after 9 months on topical rapamycin close-up; $(F)$ after 2 years

We could not see any difference in improvement in patients who had received $\mathrm{CO}_{2}$ laser treatment compared with patients who had not.

\section{DISCUSSION}

This is a retrospective observational study reflecting our experience in clinical practice using topical rapamycin. The solution was not applied daily because of side effects but also because of compliance problems, but we still had good clinical effect. This is important knowledge for clinicians, parents and patients. We used an oral solution with rapaymcin because it was impossible at that time to get an ex tempore ointment prepared in a Swedish pharmacy. We had an overall improvement of $70 \%$ which is a lower figure than what has been reported in the literature, where the majority reported improvement, which might be because of less application in our group of patients. ${ }^{[5,7,11,12,14,18]}$ The patients, with lowest response in our clinical setting, were the patients with papules and nodules. Park et al. ${ }^{[15]}$ found that papules 

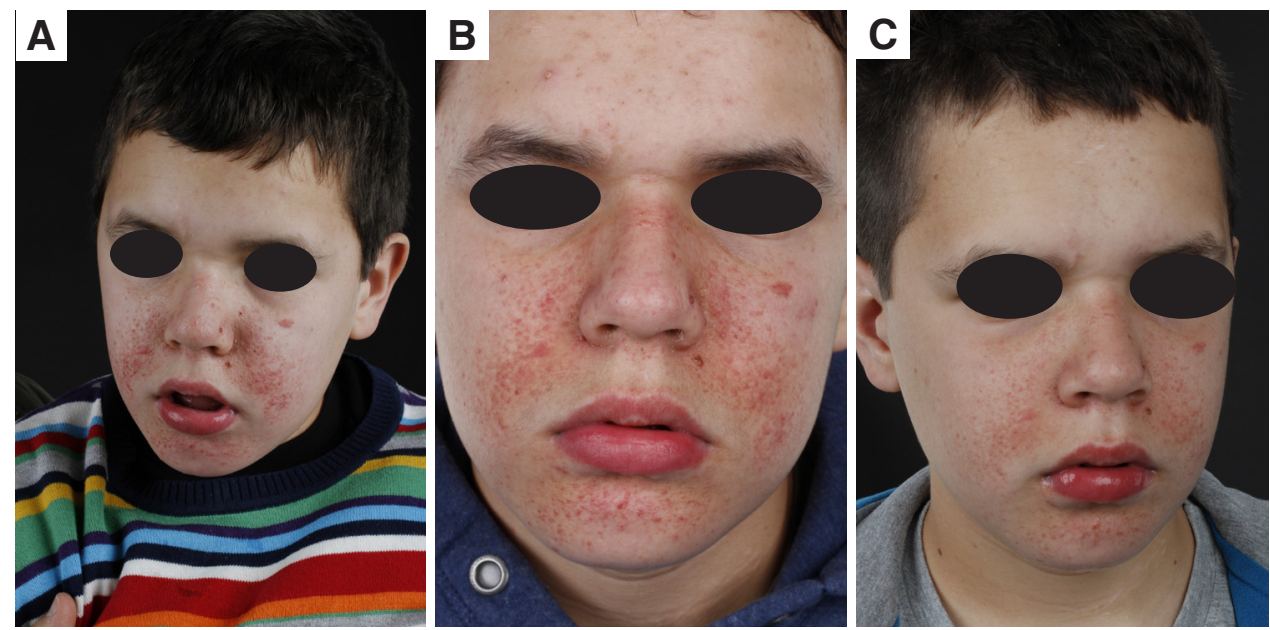

Figure 4: Patient 6. (A) before treatment; (B) after pause with rapamycine; (C) after 5 months
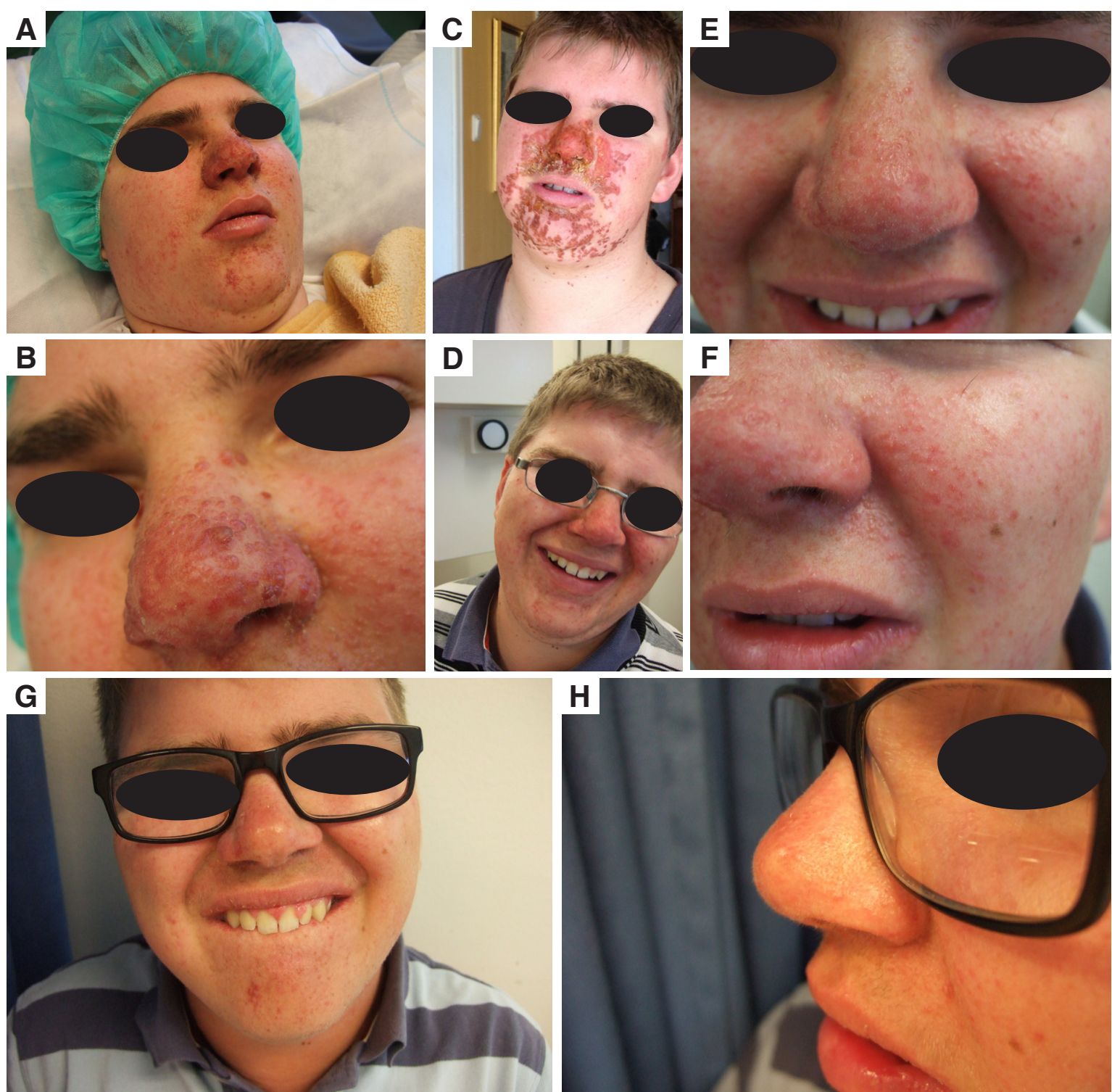

Figure 5: Patient 12. (A) before $\mathrm{CO}_{2}$ laser and rapaymcin; (B) before $\mathrm{CO}_{2}$ laser and rapamycin close-up on the nose; (C) a couple of days after $\mathrm{CO}_{2}$ laser; (D) 3 months after $\mathrm{CO}_{2}$ laser and before rapamycin; (E) 3 months after $\mathrm{CO}_{2}$ laser close-up; (F) 3 months after $\mathrm{CO}_{2}$ laser close-up on the nose; $(\mathrm{G})$ after $\mathrm{CO}_{2}$ laser and 9 months on rapamycin; $(\mathrm{H})$ after $\mathrm{CO}_{2}$ laser and 9 months on rapamycin close-up nose 

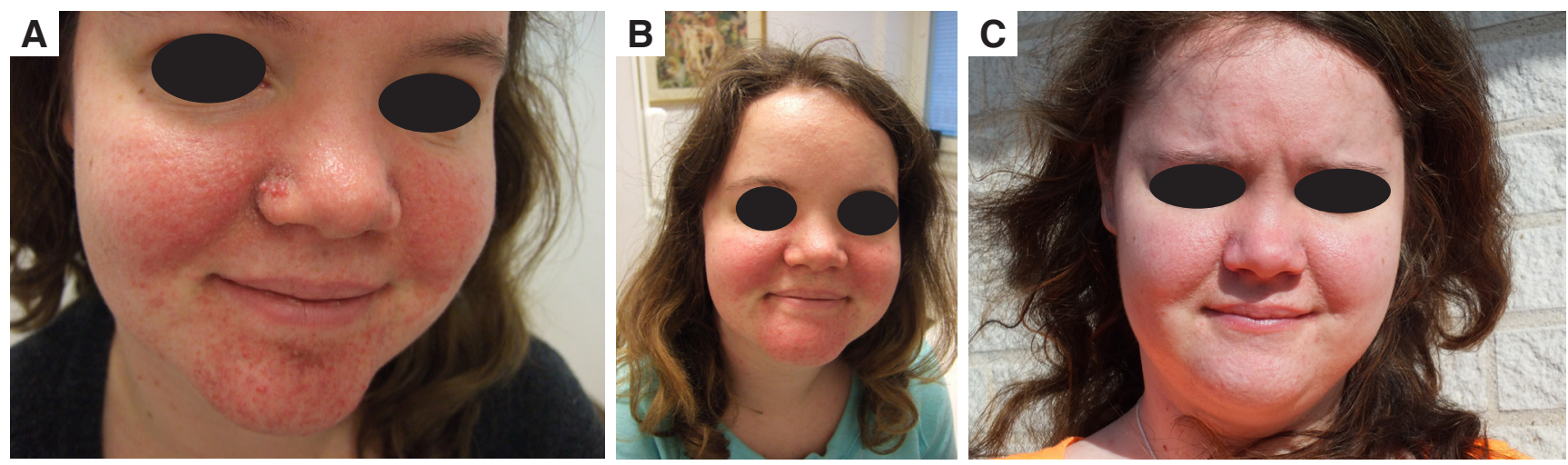

Figure 6: Patient 13. (A) before $\mathrm{CO}_{2}$ laser and rapaymcin; (B) after $\mathrm{CO}_{2}$ laser and before rapamycin; (C) after $\mathrm{CO}_{2}$ laser and rapamycin
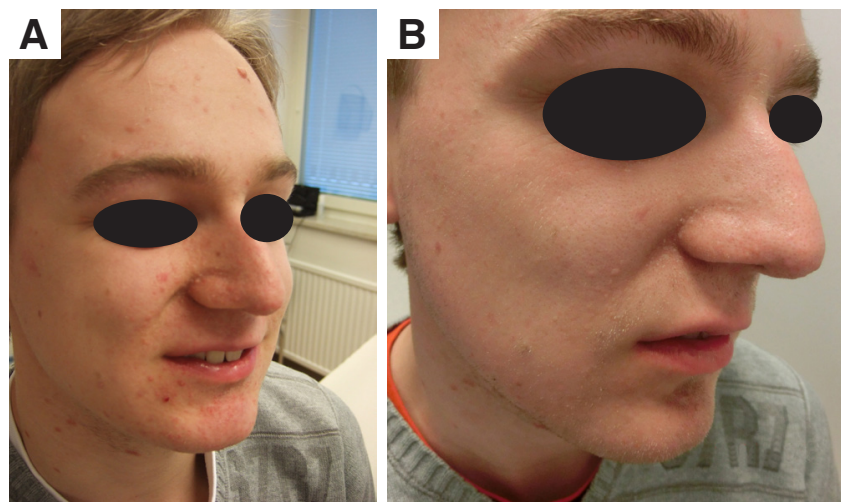

Figure 7: Patient 14. (A) after the last session of $\mathrm{CO}_{2}$ laser and before rapamycin; (B) after $\mathrm{CO}_{2}$ laser and rapamycin

larger than $4 \mathrm{~mm}$ did not respond to topical rapamycin. In our observation, all patients who paused treatment during summer relapsed, which shows that mTOR inhibition needs to be continuous. There were also tendencies for younger patients to respond better, which reflect the importance of early treatment. This is in accordance with a study by Tanaka et al. ${ }^{[14]}$ who also reported greater effects in patients younger than ten years. Five studies reported mild side effects, such as stinging and skin irritation. ${ }^{[6,12,14,16,18]}$ In our study, 8 of 23 patients had side effects, and 2 discontinued treatment because of pain and swelling. Six of the patients who got side effects could continue the treatment with no side effects if they used the solution every second to third day. We used an oral solution not designed for topical treatment, as has been reported in a previous study. ${ }^{[6]}$ This solution contains ethanol and propylenglycol, which might explain some of the side effects. On the other hand, the solution is without oily element and is therefore more suited for teenagers who besides angiofibromas could have facial acne. The ex tempore ointment that has been available lately contains petrolatum but could be a good alternative for toddlers. We could not detect rapamycin in the blood of our first 5 patients. This is in accordance to other studies in the field. ${ }^{[5,6,8,10-13,17,19]}$ So one could conclude that blood test is not needed in patients treated with topical rapamycin.

There was a tendency that longer treatment with topical rapamycin gave better effect. However, nodules responded less to topical treatment and cephlic plaque did not respond at all.

We were initially uncertain of the interaction between rapamycin and ultraviolet radiation, so the patients were in the beginning instructed to avoid sun-light. Claims of such interactions have however been refuted, as subsequent randomized controlled studies have shown a reduced risk of malignancies and non-melanoma skin cancer in transplant recipients receiving oral rapamycin. ${ }^{[20]}$

This is a retrospective observational study. There was no set schedule for the visits, as some of the patients lived far from the clinics and had other severe medical problems. Many of our patients had the diagnosis of TAND and could not participate in a standardized examination, however it was possible to get photos of all the patients.

Follow-up was done mainly through visits in person, but in 3 cases through the use of photos. The grading of treatment outcome did not employ the Facial Angiofibroma Severity Index. That scale has just recently been validated and published. ${ }^{[21]}$ So we graded the skin lesions in papules, nodules and erythema and discussed the photos with each other in order to reach consensus about our grading system. We used an oral rapamycin solution, which might have given more side effects. Patients who had not received $\mathrm{CO}_{2}$ laser treatment did respond as good as patients who had not received $\mathrm{CO}_{2}$ laser treatment. One explanation to that is probably that patients with papules bigger than $4 \mathrm{~mm}$, that is known to respond less to topical rapamycin, had received $\mathrm{CO}_{2}$ laser on these papules. ${ }^{[15]}$ 
In conclusion, topical rapamycin is a valuable tool in the treatment of angiofibromas even when treatment was performed every second to third day. Erythema and papules seem to respond in most cases, but nodules respond less well to topical rapamycin. The treatment must be continuous. Rapamycin was not detected in the blood in our patients, which is in line with other studies. Topical Rapamycin could also be a valuable complement after $\mathrm{CO}_{2}$ laser in order to maintain the improvement after the laser surgery.

\section{Acknowledgments}

Authors thank Janet Holmén for revising the English.

\section{Financial support and sponsorship}

None.

\section{Conflicts of interest}

There are no conflicts of interest.

\section{Patient consent}

All patients and/or parents gave their informed consent.

\section{Ethics approval}

This kind of clinical follow-up doesn't need formal ethics approval in Sweden.

\section{REFERENCES}

1. Osborne JP, Fryer A, Webb D. Epidemiology of tuberous sclerosis. Ann N Y Acad Sci 1991;615:125-7.

2. Krueger DA, Northrup H. Tuberous sclerosis complex surveillance and management: recommendations of the 2012 International Tuberous Sclerosis Complex Consensus Conference. Pediatr Neurol 2013;49:255-65.

3. Curatolo P, Bombardieri R, Jozwiak S. Tuberous sclerosis. Lancet 2008;372:657-68.

4. Hofbauer GF, Marcollo-Pini A, Corsenca A, Kistler AD, French LE, Wüthrich RP, Serra AL. The mTOR inhibitor rapamycin significantly improves facial angiofibroma lesions in a patient with tuberous sclerosis. Br J Dermatol 2008;159:473-5.

5. Haemel AK, O'Brian AL, Teng JM. Topical rapamycin: a novel approach to facial angiofibromas in tuberous sclerosis. Arch Dermatol 2010;146:715-8.

6. Mutizwa MM, Berk DR, Anadkat MJ. Treatment of facial angiofibromas with topical application of oral rapamycin solution (1mgmL(-1) ) in two patients with tuberous sclerosis. $\mathrm{Br} J$ Dermatol 2011;165:922-3.

7. DeKlotz CM, Ogram AE, Singh S, Dronavalli S, MacGregor JL. Dramatic improvement of facial angiofibromas in tuberous sclerosis with topical rapamycin: optimizing a treatment protocol. Arch
Dermatol 2011;147:1116-7

8. Truchuelo T, Diaz-Ley B, Rios L, Alcantara J, Jaen P. Facial angiofibromas treated with topical rapamycin: an excellent choice with fast response. Dermatol Online J 2012;18:15.

9. Kaufman McNamara E, Curtis AR, Fleischer AB Jr. Successful treatment of angiofibromata of tuberous sclerosis complex with rapamycin. J Dermatolog Treat 2012;23:46-8.

10. Knopfel N, Martin-Santiago A, Bauza A, Hervas JA. Topical 0.2\% rapamycin to treat facial angiofibromas and hypomelanotic macules in tuberous sclerosis. Actas Dermosifiliogr 2014;105:802-3.

11. Wataya-Kaneda M, Tanaka M, Nakamura A, Matsumoto S, Katayama I. A topical combination of rapamycin and tacrolimus for the treatment of angiofibroma due to tuberous sclerosis complex (TSC): a pilot study of nine Japanese patients with TSC of different disease severity. $\mathrm{Br} J$ Dermatol 2011;165:912-6.

12. Foster RS, Bint LJ, Halbert AR. Topical $0.1 \%$ rapamycin for angiofibromas in paediatric patients with tuberous sclerosis: a pilot study of four patients. Australas J Dermatol 2012;53:52-6.

13. Salido R, Garnacho-Saucedo G, Cuevas-Asencio I, Ruano J, GalánGutierrez M, Vélez A, Moreno-Giménez JC. Sustained clinical effectiveness and favorable safety profile of topical sirolimus for tuberous sclerosis - associated facial angiofibroma. J Eur Acad Dermatol Venereol 2012;26:1315-8.

14. Tanaka M, Wataya-Kaneda M, Nakamura A, Matsumoto S, Katayama I. First left-right comparative study of topical rapamycin vs. vehicle for facial angiofibromas in patients with tuberous sclerosis complex. $\mathrm{Br} J$ Dermatol 2013;169:1314-8.

15. Park J, Yun SK, Cho YS, Song KH, Kim HU. Treatment of angiofibromas in tuberous sclerosis complex: the effect of topical rapamycin and concomitant laser therapy. Dermatology 2014;228:37-41.

16. Tu J, Foster RS, Bint LJ, Halbert AR. Topical rapamycin for angiofibromas in paediatric patients with tuberous sclerosis: follow up of a pilot study and promising future directions. Australas J Dermatol 2014;55:63-9.

17. Koenig MK, Hebert AA, Roberson J, Samuels J, Slopis J, Woerner A, Northrup H. Topical rapamycin therapy to alleviate the cutaneous manifestations of tuberous sclerosis complex: a double-blind, randomized, controlled trial to evaluate the safety and efficacy of topically applied rapamycin. Drug R D 2012;12:121-6.

18. Vasani RJ. Facial angiofibromas of tuberous sclerosis treated with topical sirolimus in an Indian patient. Indian J Dermatol 2015;60:165-9.

19. Pynn EV, Collins J, Hunasehally PR, Hughes J. Successful topical rapamycin treatment for facial angiofibromata in two children. Pediatr Dermatol 2015;32:e120-3.

20. Knoll GA, Kokolo MB, Mallick R, Beck A, Buenaventura CD, Ducharme R, Barsoum R, Bernasconi C, Blydt-Hansen TD, Ekberg H, Felipe CR, Firth J, Gallon L, Gelens M, Glotz D, Gossmann J, Guba M, Morsy AA, Salgo R, Scheuermann EH, Tedesco-Silva H, Vitko S, Watson C, Fergusson DA. Effect of sirolimus on malignancy and survival after kidney transplantation: systematic review and metaanalysis of individual patient data. BMJ 2014;349:g6679.

21. Salido-Vallejo R, Ruano J, Garnacho-Saucedo G, Godoy-Gijón E, Llorca D, Gómez-Fernández C, Moreno-Giménez JC. Facial Angiofibroma Severity Index (FASI): reliability assessment of a new tool developed to measure severity and responsiveness to therapy in tuberous sclerosisassociated facial angiofibroma. Clin Exp Dermatol 2014;39:888-93. 